
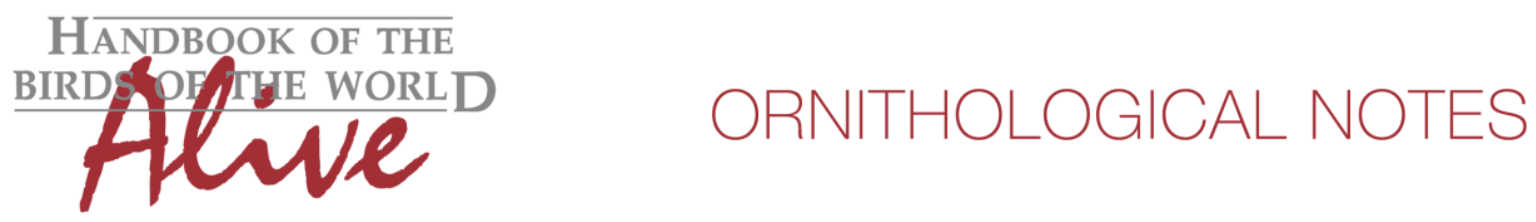

\title{
Notes on the vocalizations of Long-tailed Woodcreeper (Deconychura longicauda)
}

Peter Boesman

In the following we briefly analyze and compare voice of the different races of Long-tailed Woodcreeper (Deconychura longicauda). We also try to quantify the extent of any vocal differences using the criteria proposed by Tobias et al. (2010), as a support for taxonomic review. We have made use of sound recordings available on-line from Xeno Canto (XC) and Macaulay Library (ML).

It would seem that by voice one can classify this complex into four groups:

\section{Group typica/dariensis/minor}

There are very few recordings of this group, as they seem to be uncommon and apparently not vocal at all (no info on minor). These indicate a very different song (XC168203, ML31184, also confirmed by description in Stiles 1989): a long and fast series of short piping notes, slowly starting in the very beginning and slowing down at the very end.

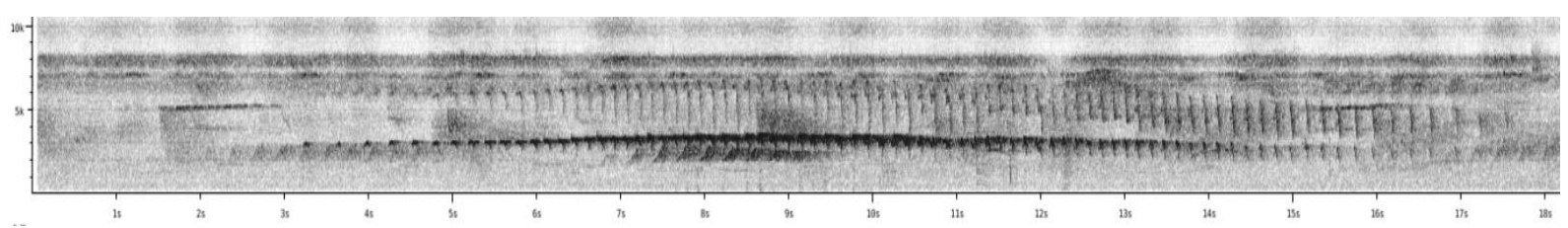

Measurements: c. $70-100$ notes, total length c. $11-20$ s, pace 0.2 , note length $0.07 \mathrm{~s}$, frequency range: $1800-3300 \mathrm{~Hz}$ highest in middle of series.

\section{Group D. I. longicauda}

All recordings of natural song (from $\mathrm{N}$ of Manaus and French Guyana) are clearly different from the next group, but less strikingly so than the previous group: a series of c. 6-10 long upslurred whistles, gradually descending in pitch.

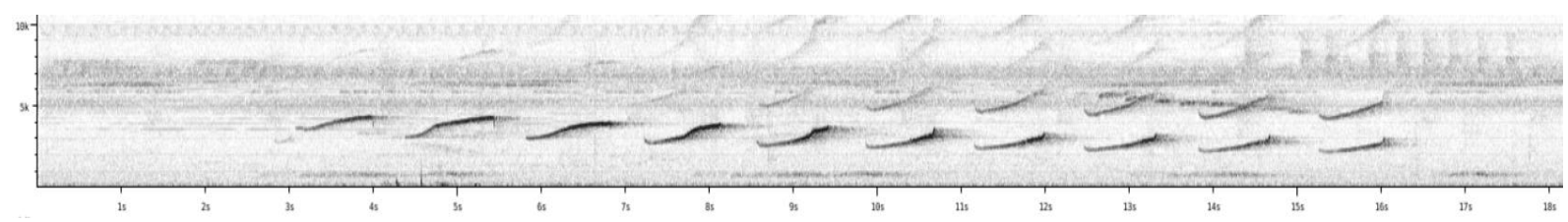

Measurements: c. 6-10 notes, total length c. 9-13s, pace 1.3-1.6, note length c. 1.0s, frequency range: c. $1800-4000 \mathrm{~Hz}$, all notes upslurred, first note highest pitched, gradually descending series. 

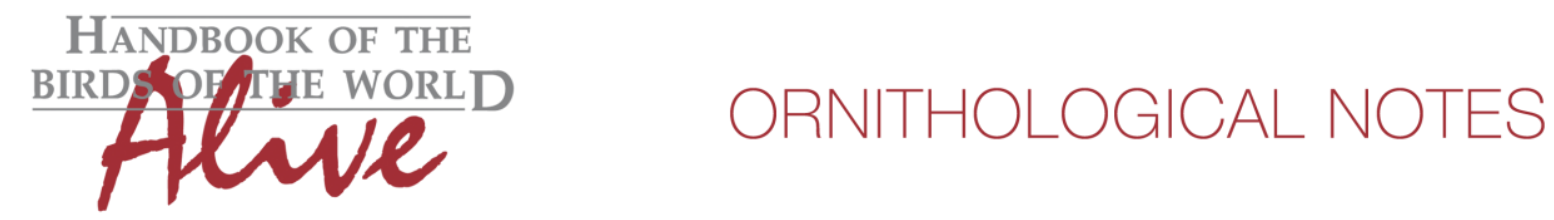

Group (connectens)/pallida/zimmeri

Song is a series of c. 8 whistles at about flat pitch, gradually descending in pitch.

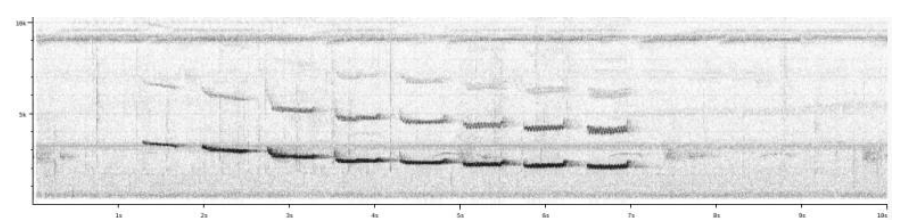

Measurements: c. 5-8 notes, total length c. 3-5.8s, pace 0.6, note length c. 0.4-0.7s, frequency range $1600-3100 \mathrm{~Hz}$, first note highest pitch, gradually descending series. (After playback these taxa give a very different fast series of burry whistles)

\section{Group 4}

There seems to be confusion about the taxonomic origin of the population occuring in the Andean foothills of East Ecuador. This may be either (part of) connectens or an undescribed taxon. In any case, song of this group is also very different (based on few samples): a series of c. 10-14 double notes, slightly descending in pitch. Every double note has a high-pitched short overslurred note and a lower-pitched longer note (somewhat like Strong-billed Woodcreeper Xiphocolaptes promeropirhynchus).

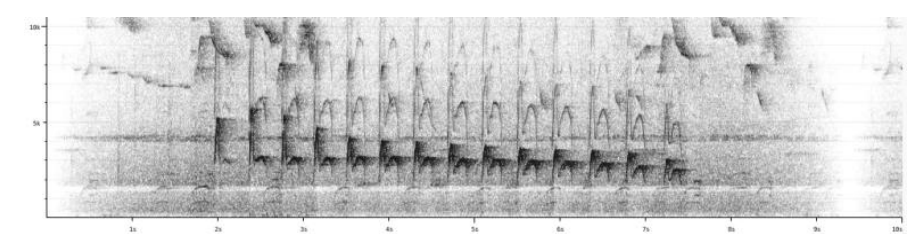

Measurements: c. $10-14$ double notes, total length $5.5 \mathrm{~s}$, pace 0.39 , note length $0.08+0.16 \mathrm{~s}$, frequency range $1700-5500 \mathrm{~Hz}$.

These vocal differences can be quantified using Tobias criteria:

Group typica/dariensis/minor has a song compared to all other groups consisting of many more notes (score 4) delivered at a much higher pace (score 3), and much shorter notes (score 4, except Group 4), resulting in a total score of 7-8

D. I. longicauda differs from group (connectens)/pallida/zimmeri by its longer note length (score 3), longer song phrase (score 3), pitch of first note (score 3) and upslurred note shape, resulting in a total score of 6 .

\section{Group (connectens)/pallida/zimmeri}

A series of c. 8 whistles at about flat pitch, gradually descending in pitch.

D.I. connectens or undescribed taxon (from foothills of E Ecuador) differs from nominate and pallida/zimmeri in note length (score 3-4), max. frequency and frequency range (score $3)$, note shape and syntax, which leads to a total score of about 6-7. 

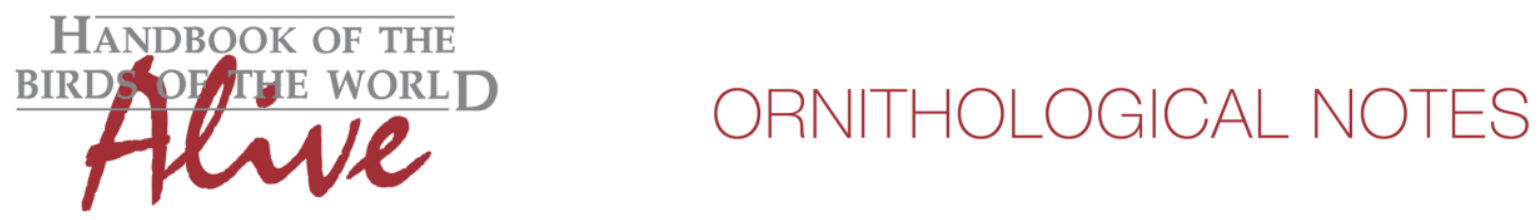

Barbosa (2010) names even 8 clades (!):

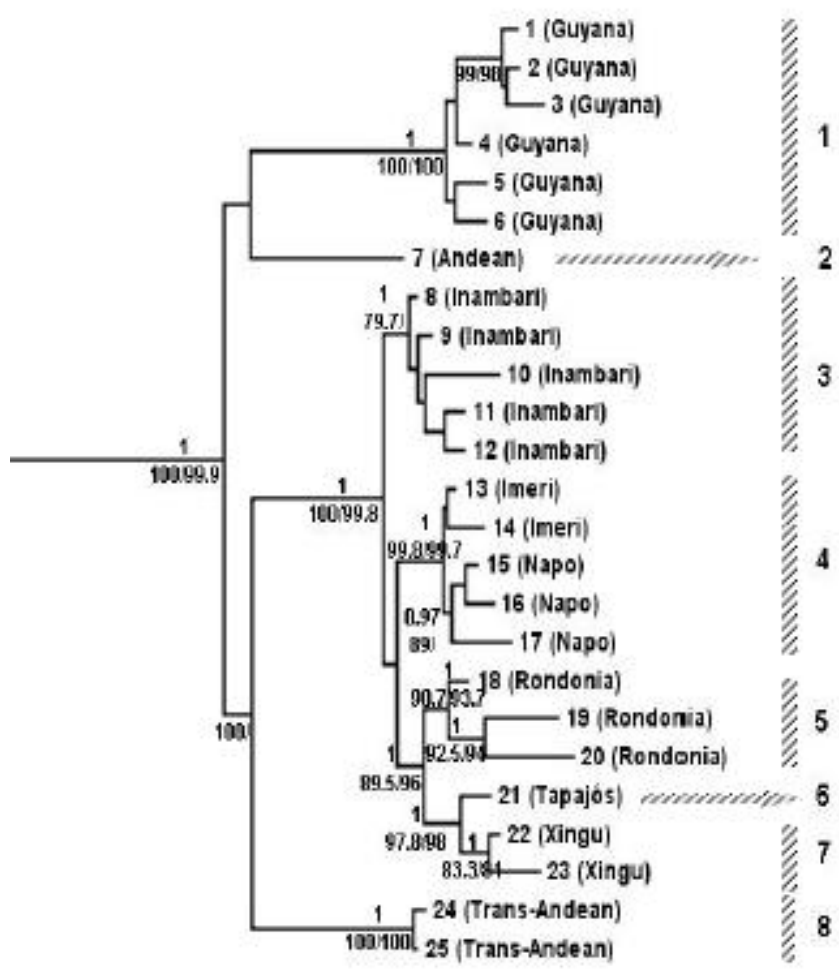

and also analyzes voice:
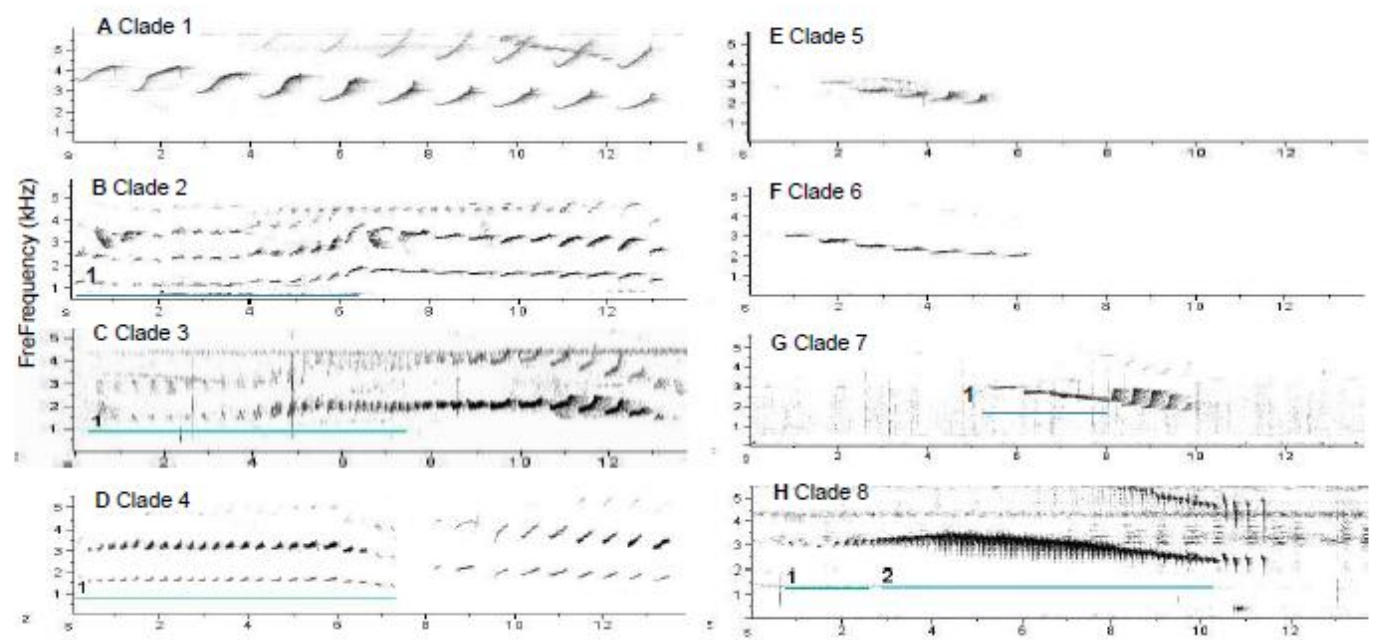

Figure 4. Loudsongs of natural populations of Deconychura longicauda (clades 1-8) recovered in a molecular phylogeny (Figure 2).

(A) Clade 1: French Guiana, La Trinité (XC 22249); (B) Clade 2: Peru, Loreto: Tierra Blanca (XC20711); (C) Clade 3: Peru, Madre de Dios, Porto Maldonado (ML35539); (D) Clade 4: Brazil, Amazonas, Iranduba, Terra Verde Lodge (ML112796); (E) Clade 5: Brazil, Amazonas, Maués, Pau-Rosa National Forest (AP 1078); (F) Clade 6: Brazil, Pará, Santarém, Tapajós National Forest (BR

A few comments need to be made here however:

Clade 2 is an unnamed taxon called 'Andean' and vocal analysis is based on 1 sample XC20711 (which was after playback). It is from the lowlands of Loreto, Peru. A more recent recording from about the same region (XC187574) is much more like 'Clade 6 type', and so are a few recordings from the Ecuadorian lowlands. At the other hand, several samples do exist for years from the Ecuadorian foothills (see XC, JVMoore productions), but these were 

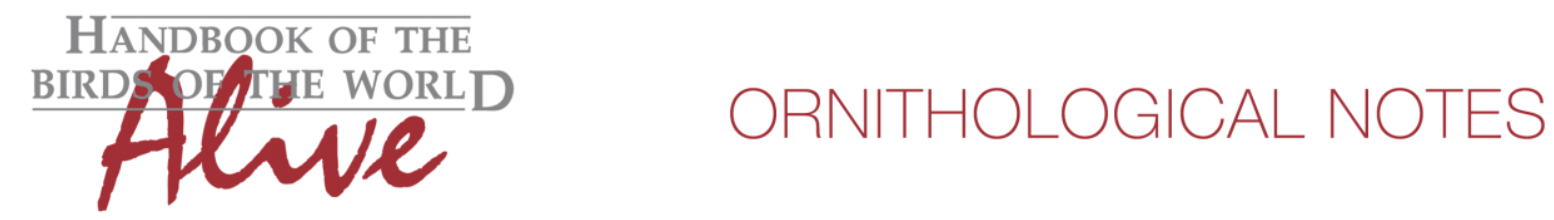

apparently discarded, despite being highly distinctive (see my group 4 in initial analysis above). In summary, there seems to be an undescribed taxon in the Andean foothills, but Barbosa may well have picked the wrong vocalization.

Clade 4 (connectens): vocal analysis is based on 1 sample ML112796 (connectens is here the range $\mathrm{W}$ of Ucayali, $\mathrm{N}$ of Amazon and $\mathrm{W}$ of Rio Negro excluding Andean foothills). This recording is clearly of an excited bird, in the notes it says it was brought in by whistling (which would rather be the 'Clade 6 type' song, which is easily whistled). Also, given that this recording is taken at just a few $\mathrm{km}$ from Manaus and is taken as representative for the complete region of NW Amazonia, is risky. At the other hand, the recordings mentioned above from the Loreto lowlands and east Ecuadorian lowlands would be a better indication of voice for this taxon.

Clade 3 (pallida): voice is said to have rising introductory notes followed by a series of descending whistles. At least a number of recordings lack these introductory notes: e.g. XC20429, XC90593, XC63376, being again rather of the 'Clade 6 type'.

Clade 5/6/7: voice seemingly lacks introductory notes, as have been recorded in Clade 3/4 for birds which are presumably excited. A few recordings do have some faster intro notes however, e.g. XC84108, after playback.

From the above comments, I believe that:

1) the undescribed Andean taxon is vocally handled equivocally

2) vocal analysis of connectens is based on a single recording from an excited bird at an extreme corner of its range, and is not in line with other recordings from the other side of its range

3) variation of voice due to playback and/or excitement is insufficiently taken into account, seriously affecting the voice comparison of pallida/zimmeri.

At least for the vocal part, I therefore consider that the conclusions of vocal distinctiveness between pallida/connectens/zimmeri are not sufficiently reliable. There may be vocal differences, but at present I don't think we have enough recordings to determine this. It would require in any case, a much more profound analysis.

For the time being, we can conclude that there are clearly 3 vocally distinct groups, and a fourth group from the Ecuadorian foothills which needs further study.

This note was finalized on 26th February 2016, using sound recordings available on-line at that moment. We would like to thank in particular the many sound recordists who placed their recordings for this species on XC and ML: Nick Athanas, Chris Benesh, Peter Boesman, Guilherme Brito, Tayler Brooks, Olivier Claessens, Paul Coopmans, Thomas Davis, Eric DeFonso, Rodrigo Dela Rosa, Sebastian Herzog, Frank Lambert, Alexander Lees, Gabriel Leite, Curtis Marantz, Luiz Mazzoni, Jeremy Minns, John V. Moore, Jonas Nilsson, Patrick O'Donnell, Ted Parker, Micah Riegner, Fabrice Schmitt, Andrew Spencer and Joseph Tobias. 


\section{References}

Barbosa, I. (2010). Revisao sistemática e filogeografica de Deconychura longicauda (Aves Dendrocolaptidae). MSc thesis. Belém, Pará.

Stiles , F.G. \& Skutch, A.F. (1989). A Guide to the Birds of Costa Rica. Christopher Helm, London.

Tobias, J.A., Seddon, N., Spottiswoode, C.N., Pilgrim, J.D., Fishpool, L.D.C. \& Collar, N.J. (2010). Quantitative criteria for species delimitation. Ibis 152(4): 724-746.

\section{Recommended citation}

Boesman, P. (2016). Notes on the vocalizations of Long-tailed Woodcreeper (Deconychura longicauda). HBW Alive Ornithological Note 78. In: Handbook of the Birds of the World Alive. Lynx Edicions, Barcelona. (retrieved from http://www.hbw.com/node/931966 on 14 July 2016). 